\title{
Fracture hospitalizations between years 2000 and 2007 in Switzerland: a trend analysis
}

\author{
K. Lippuner • A. W. Popp • P. Schwab • M. Gitlin • \\ T. Schaufler $\cdot$ C. Senn $\cdot$ R. Perrelet
}

Received: 15 July 2010 / Accepted: 21 October 2010 /Published online: 9 December 2010

(C) International Osteoporosis Foundation and National Osteoporosis Foundation 2010

\begin{abstract}
Summary In Switzerland, the total number and incidence of hospitalizations for major osteoporotic fractures increased between years 2000 and 2007, while hospitalizations due to hip fracture decreased. The cost impact of shorter hospital stays was offset by the increasing cost per day of hospitalization.

Introduction The aim of the study was to establish the trends and epidemiological characteristics of hospitalizations for major osteoporotic fractures (MOF) between years 2000 and 2007 in Switzerland.

Methods Sex- and age-specific trends in the number and crude and age-standardized incidences of hospitalized MOF (hip, clinical spine, distal radius, and proximal humerus) in women and men aged $\geq 45$ years were analyzed, together with the number of hospital days and cost of hospitalization, based on data from the Swiss Federal Statistical Office hospital database and population statistics.

Results Between 2000 and 2007, the absolute number of hospitalizations for MOF increased by $15.9 \%$ in women
\end{abstract}

K. Lippuner $(\bowtie) \cdot$ A. W. Popp $\cdot$ C. Senn $\cdot$ R. Perrelet

Osteoporosis Policlinic, Inselspital, Bern University Hospital,

University of Bern,

3010, Bern, Switzerland

e-mail: kurt.lippuner@insel.ch

P. Schwab

Swiss Federal Statistical Office,

Neuchâtel, Switzerland

M. Gitlin

Amgen (Europe) $\mathrm{GmbH}$,

Zug, Switzerland

T. Schaufler

Amgen (Switzerland) AG,

Zug, Switzerland and $20.0 \%$ in men, mainly due to an increased number of nonhip fractures $(+37.7 \%$ in women and $+39.7 \%$ in men). Hospitalizations for hip fractures were comparatively stable $(-1.8 \%$ in women and $+3.3 \%$ in men). In a rapidly aging population, in which the number of individuals aged $\geq 45$ years grew by $11.1 \%$ (women) and $14.6 \%$ (men) over the study period, the crude and age-standardized incidences of hospitalizations decreased for hip fractures and increased for non-hip MOF, both in women and men. The length of hospital stay decreased for all MOF in women and men, the cost impact of which was offset by an increase in the daily costs of hospitalization.

Conclusions Between years 2000 and 2007, hospitalizations for MOF continued to increase in Switzerland, driven by an increasing number and incidence of hospitalizations for non-hip fractures, although the incidence of hip fractures has declined.

Keywords Cost · Epidemiology · Fractures · Hip · Osteoporosis $\cdot$ Switzerland

\section{Introduction}

Osteoporosis is defined as "a systemic skeletal disease characterized by low bone mass and microarchitectural deterioration of bone tissue, with a consequent increase in bone fragility and susceptibility to fracture" [1]. While according to this definition a patient with osteoporosis is at increased risk for fracture at any site, "typical" osteoporotic fractures occur at the hip, spine, distal forearm, and proximal humerus. The latter are also referred to as major osteoporotic fractures [2-4].

Several recent publications have indicated a possible reversal of the secular trend of hip fractures in the USA [5- 
7], Canada [8, 9], Japan [10], Finland [11], Denmark [12], France [13], and in the region of Geneva, Switzerland [14, 15] but not in Austria [16], Spain [17], or Germany [18, 19]. None of these publications reported trends of major osteoporotic fractures other than hip fractures.

The aim of the present analysis was to review the trends and epidemiological characteristics of major osteoporotic fractures in Switzerland, in female and male patients aged 45 years or older, between years 2000 and 2007. Predefined parameters of interest were absolute number and incidence of fracture hospitalizations, number of hospital days due to fractures, and cost of hospitalizations for major osteoporotic fractures.

\section{Methods}

We chose to report the characteristics of major osteoporotic fractures instead of fractures due to osteoporosis derived from all fractures multiplied by an osteoporosis attribution rate used in earlier publications [20, 21]. In year $2000,51 \%$ and $24 \%$ of all hospitalizations for fracture in women and men, respectively, were attributed to osteoporosis [20]. Not using the attribution rates, as in the present approach, leads to a total number of fractures leading to hospitalization due to major osteoporotic fractures in year 2000 corresponding to only $77 \%$ and $72 \%$ of the attributed fractures in women and men, respectively. Therefore, the absolute numbers, incidences, hospital days, and related costs detailed in the following analysis should be considered conservative.

\section{Source of hospital statistics}

The administrative and medical statistics database of the Swiss Federal Statistical Office (SFSO) was used. All Swiss acute hospitals, rehabilitation centers, and specialized clinics are obliged to supply their administrative (finance, human resources, number of beds, and patient admissions) and medical data (age, sex, number of hospitalized fractures coded in accordance with the International Classification of Diseases 10th Edition (ICD-10) requirements, and duration of hospitalization) to the SFSO. Data collection is initiated and coordinated by the SFSO following stringent quality control measures. Since 1998, each reporting hospital uses a plausibility testing software (currently MedPlaus version 5.0) developed by the SFSO [22]. More than 700 plausibility checks in 4 categories (single variable testing, pooled variable testing (cross-schecks), multiple interdependent variable testing, diagnostic code vs. treatment code testing) are performed. Generated log files categorize findings as "errors" for mandatory correction, "alerts" for recommended correction, and "notes" for optional correc- tion. The corrected dataset is sent to the corresponding cantonal health department which ensures consistency in reporting across hospitals within a canton. Inconsistencies are returned to the reporting hospital for correction in line with source data and cantonal requirements. Thereafter, the datasets are sent by all cantons to the SFSO, which performs the last plausibility testing at the federal level, ensuring consistency across cantons. As an example, in year 2001 , at the federal level, $4.6 \%$ of the diagnostic codes were identified as not plausible [23]. Only medical data from Swiss acute hospital settings were retained for the present analysis. Data from rehabilitation centers and specialized clinics were excluded to prevent double counting. Although reporting is mandatory, some records were missing; the degree of completeness for all records for years $2000-2007$ was $81.2 \%, 84.9 \%, 95.0 \%, 94.1 \%$, $96.2 \%, 98.2 \%, 98.5 \%$, and $98.6 \%$, respectively. All raw data were extrapolated pro-rata to $100 \%$ to become representative for Switzerland as a whole. Data on the Swiss population structure between 2000 and 2007, split by 5 -year age groups and sex, were also obtained from the SFSO.

Hospitalized major osteoporotic fractures in years 2000 through 2007

Raw data for the number of fractures leading to hospitalizations in the acute care setting and the corresponding duration of hospitalization, categorized as described above, were obtained for major osteoporotic fractures (fractures of the hip, spine, distal radius, and proximal humerus), in women and men aged $\geq 45$ years. Hip fractures were defined as fractures with ICD-10 codes S72.0 (fracture of the femoral neck), S72.1 (pertrochanteric fracture), and S72.2 (subtrochanteric fracture). Spine fractures were defined as codes S22.0 (fracture of the thoracic spine), S22.1 (multiple fractures of the thoracic spine), S32.0 (fracture of the lumbar spine), S32.7 (multiple fractures of the lumbar spine), and S32.8 (other fractures of the lumbar spine). Fractures of the distal forearm were defined as S52.5 (fracture of the distal radius) and S52.6 (combined fracture of the distal radius/ulna). Finally, fractures of the proximal humerus were identified by the code S42.2 (fracture of the proximal humerus).

Epidemiological and health economic outcomes

The crude and age-standardized incidences of hospitalizations, the number of patient-days spent in the hospital, and the mean length of hospital stay (LOS) per patient were calculated by 5 -year age groups starting from age 45 onwards and by sex, for all major osteoporotic fractures grouped into the fracture types defined above. Annual 
crude incidences per 100,000 persons in years 2000-2007 were calculated for hip fractures and non-hip major osteoporotic fractures as defined above for each sex and for the predefined 5-year age groups, starting from age 45 onwards. As first suggested by Lewinnek et al. [24], annual age-standardized fracture incidences per 100,000 persons and related $95 \%$ confidence intervals were calculated for the same categories of sex, age, and fractures with direct adjustment to the year 2000 age structure to control for the rapid aging of the Swiss population and to allow for comparison over time. The relevant number of exposed persons was derived from the official population statistics of the SFSO. Incidences by sex and by 5-year age group for hip and non-hip major osteoporotic fractures (MOF) in year 2007 were compared to the corresponding incidences in reference year 2000 by calculating the standardized incidence rate ratio and its 95\% confidence interval. Yearly changes in age-specific fracture subgroups (hip and major osteoporotic non-hip fractures) were assessed by sex using a chi-square test for linear trends. All calculations were done with the statistical software StatsDirect version 2.7.7 developed by StatsDirect Ltd, Altrincham, Cheshire, UK.

To assess the costs of fracture hospitalization in 20002007, specific assumptions and methods were applied as described below. As no specific cost data by fracture diagnosis code is available, the average cost per day of acute care hospitalization in Swiss Francs (CHF) was obtained from the yearly hospital statistics database of the SFSO for each year of analysis [25]. The cost per day utilized for each year was not inflation adjusted.

\section{Results}

Swiss population structure

Between 2000 and 2007, the number of women and men in the Swiss population increased, from 3.67 million to 3.85 million and from 3.51 million to 3.70 million, respectively, representing an average annual population increase during this period of $0.6 \%$ for all women and $0.7 \%$ for all men. For both sexes, however, the number of individuals aged $\geq 45$ years grew faster than the total population (by $11.1 \%$ and $14.6 \%$ in women and men, respectively, over the study period), so that as a proportion of the total population, this age group increased from $42.1 \%$ to $44.7 \%$ (women) and from $37.9 \%$ to $41.2 \%$ (men).

Hospitalizations for major osteoporotic fractures

Between 2000 and 2007, the absolute number of acute care hospitalizations for major osteoporotic fractures in patients aged $\geq 45$ years increased by $15.9 \%$ in women and $20.0 \%$ in men (Table 1), driven mainly by increases in the number of hospitalizations for non-hip fractures $(37.7 \%$ and $39.7 \%$, respectively). The corresponding changes in the number of hip fracture hospitalizations were $-1.8 \%$ in women and $+3.3 \%$ in men. The number of hospitalizations for hip fractures decreased by $0.2 \%$ per year in women and increased by $0.4 \%$ per year in men. In contrast, the number of hospitalizations for major osteoporotic fractures other than hip fractures increased by $4.1 \%$ per year in women and by $4.3 \%$ per year in men during the same period.

As shown in Tables 2 (women) and 3 (men), the overall age-standardized incidence of hospitalizations for hip fractures per 100,000 person-years in patients aged $\geq 45$ years had significantly decreased by $14 \%$ in year 2007 compared to year 2000, both in women (from 496 (95\% CI 485 to 507) to $428(95 \%$ CI 419 to 438$)$ ) and in men (from 191 (95\% CI 183 to 198$)$ to $164(95 \%$ CI 158 to 171$))$. The linear trend of decrease during the 8 years of observation was significant in both sexes $(P=0.002$ in women and $P=0.001$ in men, in Figs. 1 and 2, respectively). Significant decreases in hip fracture incidences were observed in women older than 65 years of age and in 65-79-year-old men. The largest decreases in hip fracture incidence were observed in 65-74year-old women and men, reaching $-26 \%$ and $-24 \%$, respectively. Conversely, the age-standardized incidence of hospitalizations for non-hip major osteoporotic fractures was significantly increased in year 2007 compared to 2000 in both sexes, by $23 \%$ in women (from 405 (95\% CI 395 to 415 ) to 499 (95\% CI 488 to 510) per 100,000 person-years) and by $20 \%$ in men (from 160 (95\% CI 153 to 167 ) to 193 (95\% CI 186 to 200) per 100,000 person-years). The linear trend of increase during the 8 years of observation was significant in women $(P<0.001$, Fig. 1) but not in men $(P=0.149$, Fig. 2). Significant increases in agestandardized non-hip MOF were observed in all age groups in women (Table 2) and in selected age groups ( 55 to 59,65 to 74 , and $\geq 80$ years) in men (Table 3 ). The largest increase in non-hip MOF incidence was observed in 55-64-year-old women, reaching $+44 \%$ and in men after the age of 70 , reaching $+48 \%$.

Patient-days in hospital and mean length of stay

The number of patient-days per year spent in acute hospital settings for major osteoporotic fractures in patients aged $\geq 45$ years decreased from 224,244 in 2000 to 185,010 in 2007 in women (a decrease of 17.5\%) and from 71,477 to $62,904$ in men $(-12.0 \%)$ (Table 4$)$. The decreasing trend during the 8-year observation period was significant in both sexes $(P<0.001)$. The annual percent change in patient-days over the period was $-2.4 \%$ for women and $-1.6 \%$ for men. This change was due mainly to steady decreases in both sexes in patient-days attributable to hip fractures. For other 
Table 1 Absolute number of hospitalized major osteoporotic fractures in women and men from 2000 to 2007

\begin{tabular}{|c|c|c|c|c|c|c|c|c|c|c|}
\hline & 2000 & 2001 & 2002 & 2003 & 2004 & 2005 & 2006 & 2007 & $\begin{array}{l}\text { Change } 2007 \\
\text { vs } 2000(\%)\end{array}$ & $\begin{array}{l}\text { Change per } \\
\text { year }(\%)\end{array}$ \\
\hline \multicolumn{11}{|l|}{ Women } \\
\hline Hip & 7,684 & 8,375 & 7,896 & 7,895 & 7,522 & 7,307 & 7,402 & 7,544 & -1.8 & -0.2 \\
\hline Spine & 1,295 & 1,454 & 1,477 & 1,540 & 1,493 & 1,586 & 1,649 & 1,844 & 42.4 & 4.5 \\
\hline Distal radius & 2,893 & 3,254 & 3,438 & 3,891 & 3,881 & 4,381 & 4,668 & 4,234 & 46.4 & 4.9 \\
\hline Proximal humerus & 2,076 & 2,217 & 2,308 & 2,291 & 2,542 & 2,407 & 2,636 & 2,549 & 22.8 & 2.6 \\
\hline Subtotal, non-hip & 6,264 & $6^{\prime} 925$ & 7,223 & 7,722 & 7,916 & 8,374 & 8,953 & 8,627 & 37.7 & 4.1 \\
\hline Total & 13,948 & 15,300 & 15,119 & 15,617 & 15,438 & 15,681 & 16,355 & 16,171 & 15.9 & 1.9 \\
\hline \multicolumn{11}{|l|}{ Men } \\
\hline Hip & 2,538 & 2,667 & 2,567 & 2,592 & 2,527 & 2,448 & 2,622 & 2,623 & 3.3 & 0.4 \\
\hline Spine & 854 & 911 & 821 & 929 & 962 & 950 & 1,010 & 1,150 & 34.7 & 3.8 \\
\hline Distal radius & 635 & 719 & 752 & 857 & 829 & 936 & 1,009 & 958 & 50.9 & 5.3 \\
\hline Proximal humerus & 643 & 778 & 699 & 761 & 793 & 926 & 855 & 871 & 35.5 & 3.9 \\
\hline Subtotal, non-hip & 2,132 & 2,408 & 2,272 & 2,547 & 2,584 & 2,812 & 2,874 & 2,979 & 39.7 & 4.3 \\
\hline Total & 4,670 & 5,075 & 4,839 & 5,139 & 5,111 & 5,260 & 5,496 & 5,602 & 20.0 & 2.3 \\
\hline
\end{tabular}

fractures, the changes in number of patient-days over the period were smaller than for hip fractures.

The mean LOS for major osteoporotic fracture treatment steadily decreased between 2000 and 2007, from 16.1 to 11.4 days in women (-29.2\%) and from 15.3 to 11.2 days in men $(-26.8 \%)$. The mean annual change in LOS was $-4.2 \%$ in women and $-3.8 \%$ in men, with a similar magnitude across all fractures, so that hip fractures remained the fracture type with the longest hospitalization duration in year 2007.

Cost of hospitalizations for major osteoporotic fractures

As described above, the average LOS for patients hospitalized because of fractures decreased substantially over the period between 2000 and 2007. The effect of this was counterbalanced, however, by rising hospital costs: the mean cost per day of hospitalization increased from $\mathrm{CHF}$ 996.00 to CHF 1,543.00, over the same period, a rise of $55 \%$. The combined effect of these two changes was to increase total hospital costs for all major osteoporotic fractures from CHF 223.5 millions in year 2000 to CHF $285.4(+27.7 \%)$ in year 2007 in women and from 71.2 to 97.1 millions $(+36.4 \%)$ in men during the same period (Table 4). These increasing trends during the 8-year observation period did not reach statistical significance, neither in women $(P=0.086)$ nor in men $(P=0.258)$. While the costs of hip fractures increased by $2.0 \%$ and $2.5 \%$ per year between 2000 and 2007 in women and men, respectively, the corresponding cost of non-hip fractures increased by $5.0 \%$ and $6.4 \%$ per year. As shown in Fig. 3, the economic benefit of reductions in the LOS has been offset by the higher daily cost of hospitalization - indeed, mean cost per patient increased by $1.2 \%$ per year in women and by $1.6 \%$ per year in men, corresponding to an overall increase in the cost per patient hospitalized for a major osteoporotic fracture of $10.2 \%$ (women) and $13.6 \%$ (men) over the 8 years of observation.

\section{Discussion}

This epidemiological analysis of the hospitalization rates and characteristics of major osteoporotic fractures (hip, spine, distal radius, and proximal humerus) in acute hospital settings in Switzerland suggests a nationwide reversal of the secular trend of hip fractures. The present results show for the first time that in a rapidly aging population, the incidence of hospitalizations for major osteoporotic fractures other than hip fractures followed an opposite trend. Furthermore, the economic benefit of the reduced duration of hospitalization for all major osteoporotic fractures was offset by the simultaneous increase in the cost per day of hospitalization.

Switzerland ranks second worldwide after Japan with regard to the proportion of elderly in the resident population [26]. In Switzerland, life expectancy at birth is among the highest worldwide (82.5 years for women and 76.7 years for men in 2001) [27] and is continuously increasing, reaching 84.2 and 79.4 years in year 2007 in women and men, respectively [28]. According to the demographic scenarios from the SFSO, this increasing trend will not level off before year 2050, by when the population older than 65 years of age will almost have doubled [29]. 


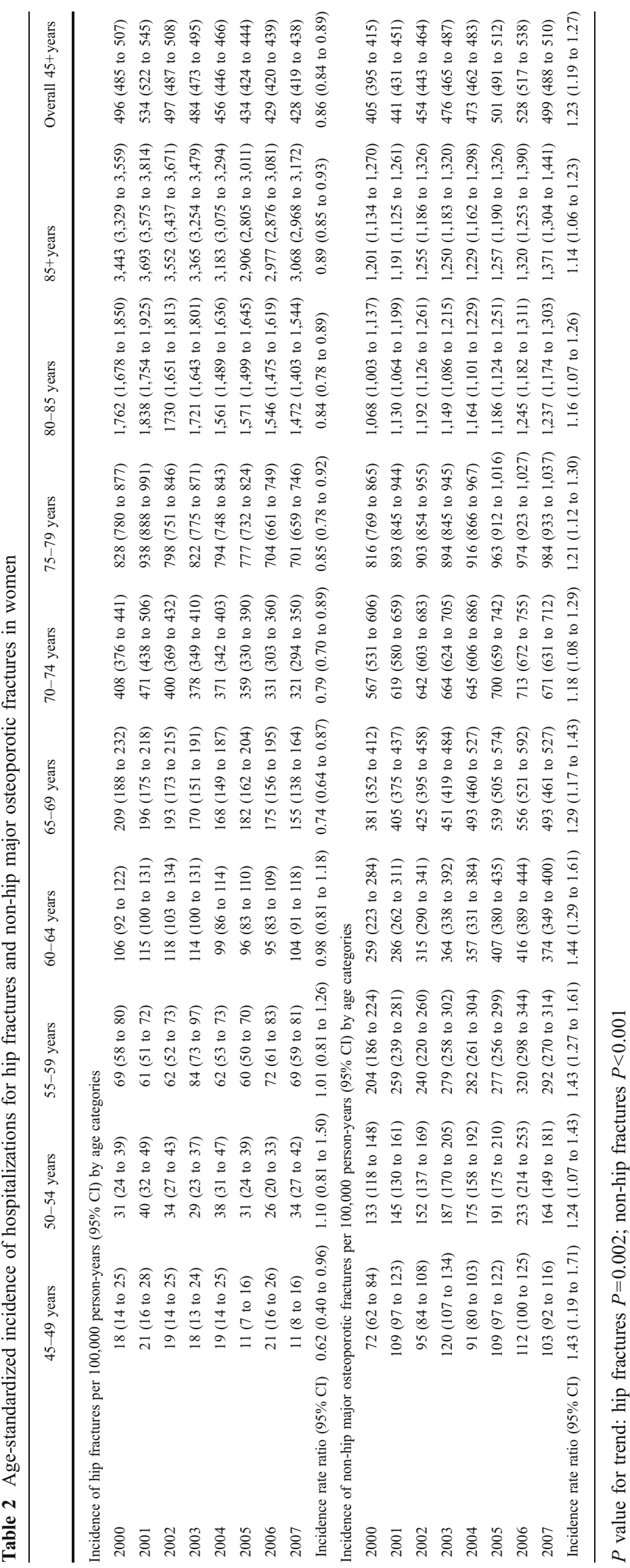




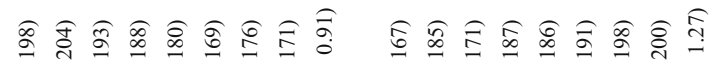

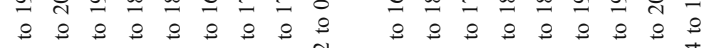

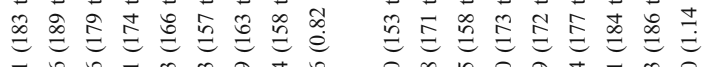

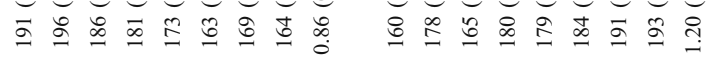

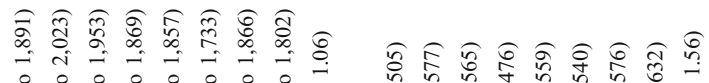

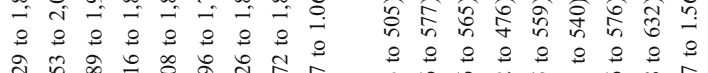

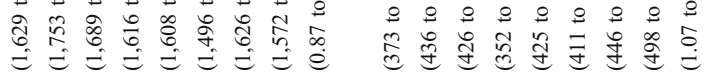

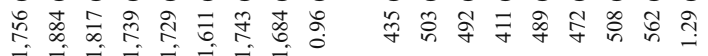

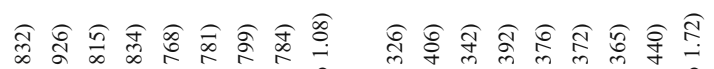

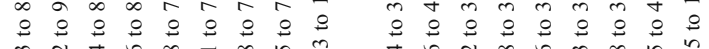

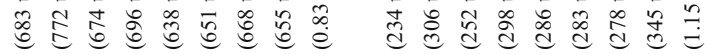

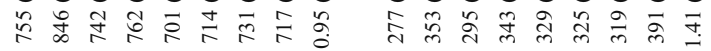

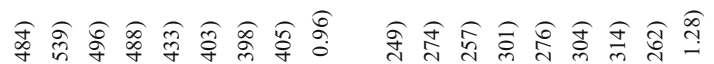

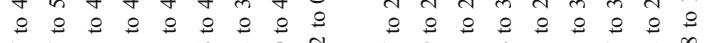

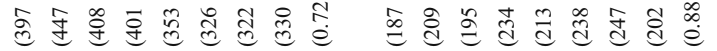

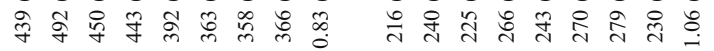

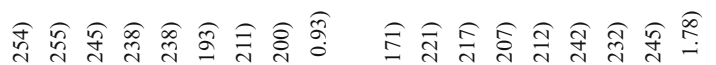

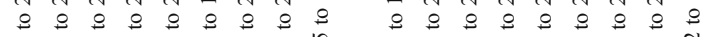

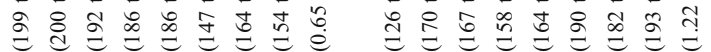

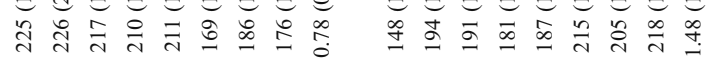

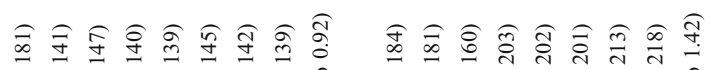

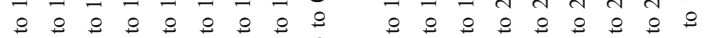

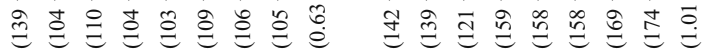

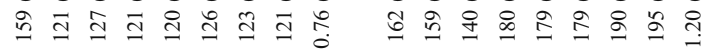

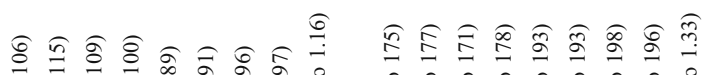

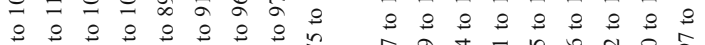

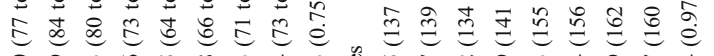

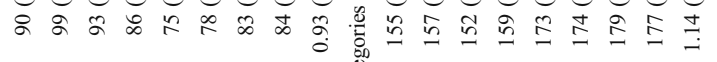
สำ

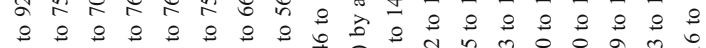

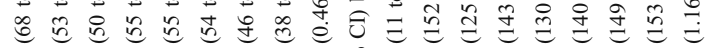

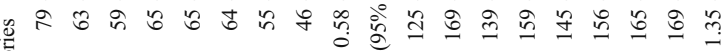
突

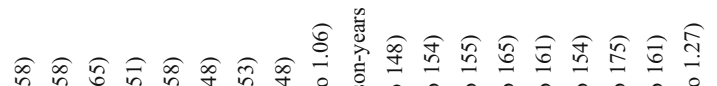

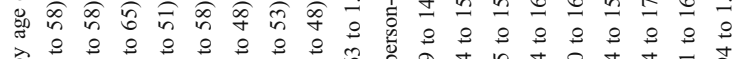

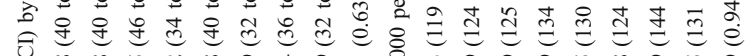

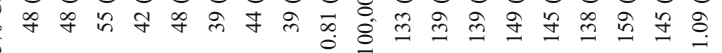
焉

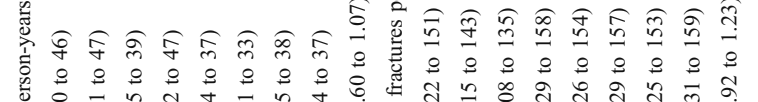
कू 各 

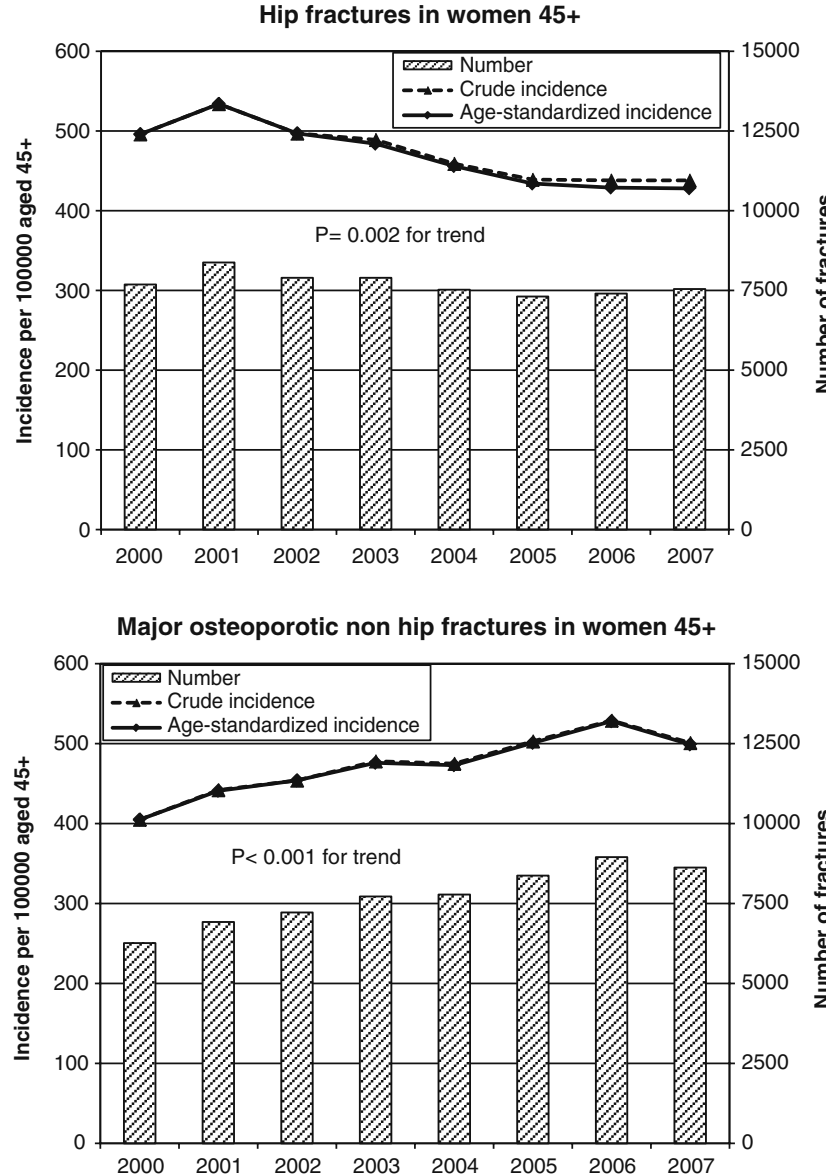

Fig. 1 Hip fractures and non-hip major osteoporotic fractures in women aged 45 years and older. Total number and crude and agestandardized incidences per 100,000 person-years

Therefore, the current trend indicating a reduction of hip fracture incidence will not be sufficient to reduce in the number of hip fractures in the coming decades. Furthermore, any reduction in hip fracture incidence may be more than offset by the increasing incidences of hospitalizations of major osteoporotic fractures other than hip.

The incidence of hip fractures decreased in all age groups between year 2000 and year 2007, indicating that the reported reversal of the secular trend of hip fractures in the region of Geneva between years 1991 and 2000 [14] may be a nationwide phenomenon that continued at least until year 2007. Patients with hip fractures are usually hospitalized for surgical repair, so that the incidence of hospitalizations may be considered as a reliable approximation of their overall incidence. As already done by others who reported similar findings [8, 12, 14], we can only speculate about the potential causes of such a reversal. First, this decreasing incidence was observed in both sexes, although more pronounced in women than in men. Second, it was observed in all age groups, although most pronounced in 65-74-year-old women and in 45-64-year-old men. This is consistent with earlier observations from Sweden that indicated a right-shift of the hip fracture incidence curve in women [30]. Women in this age group may have benefited from the "golden days" of hormone replacement therapy, which was shown to reduce the risk of hip fracture, until safety concerns regarding the HRTinduced increased risk of breast cancer, stroke, nonfatal myocardial infarction, and pulmonary embolism [31, 32] gained considerable public attention and led many physicians and women, including those in Switzerland, to restrict their usage [33]. This age group is also the typical category of the population in which osteoporosis is diagnosed and treated with a bone active substance proven to reduce fracture risk at the hip, generally a bisphosphonate [34, 35]. However, as suggested by others, the decrease in hip fractures may be much too large to be explained solely by an increase in the use of osteoporosis treatment $[8,12,36]$. Furthermore, a reduction in hip fracture incidence was also observed in men who are not the primary target group for interventions against osteoporosis in Switzerland. The awareness and use of vitamin D in the elderly and very
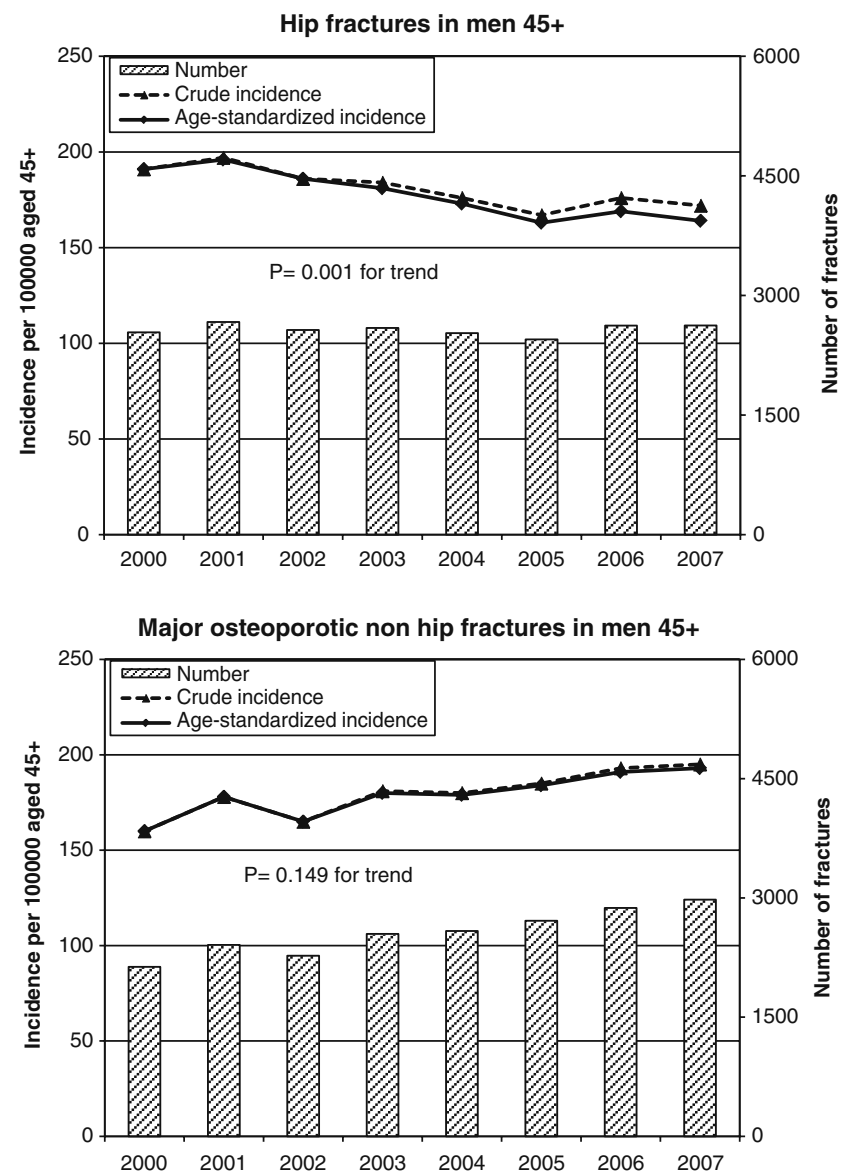

Fig. 2 Hip fractures and non-hip major osteoporotic fractures in men aged 45 years and older. Total number and crude and age-standardized incidences per 100,000 person-years 
Table 4 Patient-days spent in acute care hospitals and annual cost of hospitalizations (in millions CHF) for major osteoporotic fractures in Switzerland

\begin{tabular}{|c|c|c|c|c|c|c|c|c|c|c|}
\hline & 2000 & 2001 & 2002 & 2003 & 2004 & 2005 & 2006 & 2007 & $\begin{array}{l}\text { Change } 2007 \\
\text { vs. } 2000(\%)\end{array}$ & $\begin{array}{l}\text { Change per } \\
\text { year }(\%)\end{array}$ \\
\hline \multicolumn{11}{|l|}{ Patient-days } \\
\hline \multicolumn{11}{|l|}{ Women } \\
\hline Hip & 146,302 & 149,380 & 141,410 & 138,974 & 124,271 & 116,910 & 110,475 & 110,819 & -24.3 & -3.4 \\
\hline Spine & 21,600 & 21,484 & 24,630 & 24,082 & 20,693 & 21,279 & 22,064 & 22,624 & +4.7 & +0.6 \\
\hline Distal radius & 25,200 & 26,868 & 23,929 & 23,934 & 24,453 & 25,003 & 25,755 & 23,767 & -5.7 & -0.7 \\
\hline Proximal humerus & 31,143 & 31,459 & 30,536 & 28,520 & 29,406 & 27,627 & 29,777 & 27,798 & -10.7 & -1.4 \\
\hline Total days & 224,244 & 229,192 & 220,506 & 215,510 & 198,823 & 190,818 & 188,071 & 185,010 & -17.5 & -2.4 \\
\hline \multicolumn{11}{|l|}{ Men } \\
\hline Hip & 47,840 & 45,802 & 44,625 & 43,341 & 40,110 & 37,144 & 39,484 & 37,735 & -21.1 & -2.9 \\
\hline Spine & 11,830 & 12,300 & 11,228 & 11,472 & 11,073 & 9,981 & 11,423 & 11,901 & +0.6 & +0.1 \\
\hline Distal radius & 3,820 & 4,372 & 4,160 & 4,864 & 4,427 & 4,929 & 5,045 & 4,559 & +19.3 & +2.2 \\
\hline Proximal humerus & 7,986 & 8,630 & 7,255 & 8,476 & 8,262 & 8,517 & 8,227 & 8,709 & +9.1 & +1.1 \\
\hline Total days & 71,477 & 71,105 & 67,268 & 68,153 & 63,872 & 60,571 & 64,179 & 62,904 & -12.0 & -1.6 \\
\hline \multicolumn{11}{|c|}{ Hospitalization cost (CHF, millions) } \\
\hline \multicolumn{11}{|l|}{ Women } \\
\hline Hip & 145.8 & 170.1 & 174.7 & 180.3 & 166.2 & 165.3 & 161.9 & 171.0 & +17.3 & +2.0 \\
\hline Spine & 21.5 & 24.5 & 30.4 & 31.2 & 27.7 & 30.1 & 32.3 & 34.9 & +62.3 & +6.2 \\
\hline Distal radius & 25.1 & 30.6 & 29.6 & 31.1 & 32.7 & 35.3 & 37.7 & 36.7 & +46.2 & +4.8 \\
\hline Proximal humerus & 31.0 & 35.8 & 37.7 & 37.0 & 39.3 & 39.1 & 43.6 & 42.9 & +38.4 & +4.1 \\
\hline Total & 223.5 & 260.9 & 272.4 & 279.6 & 265.9 & 269.7 & 275.6 & 285.4 & +27.7 & +3.1 \\
\hline \multicolumn{11}{|l|}{ Men } \\
\hline Hip & 47.7 & 52.1 & 55.1 & 56.2 & 53.7 & 52.5 & 57.9 & 58.2 & +22.0 & +2.5 \\
\hline Spine & 11.8 & 14.0 & 13.9 & 14.9 & 14.8 & 14.1 & 16.7 & 18.4 & +55.9 & +5.7 \\
\hline Distal radius & 3.8 & 5.0 & 5.1 & 6.3 & 5.9 & 7.0 & 7.4 & 7.0 & +84.2 & +8.0 \\
\hline Proximal humerus & 8.0 & 9.8 & 9.0 & 11.0 & 11.1 & 12.0 & 12.1 & 13.4 & +67.5 & +6.8 \\
\hline Total & 71.2 & 81.0 & 83.1 & 88.4 & 85.4 & 85.6 & 94.0 & 97.1 & +36.4 & +3.9 \\
\hline
\end{tabular}

$P$ value for trends: patient-days women $(P<0.001)$ and men $(P<0.001)$; hospitalization cost women $(P=0.086)$ and men $(P=0.258)$

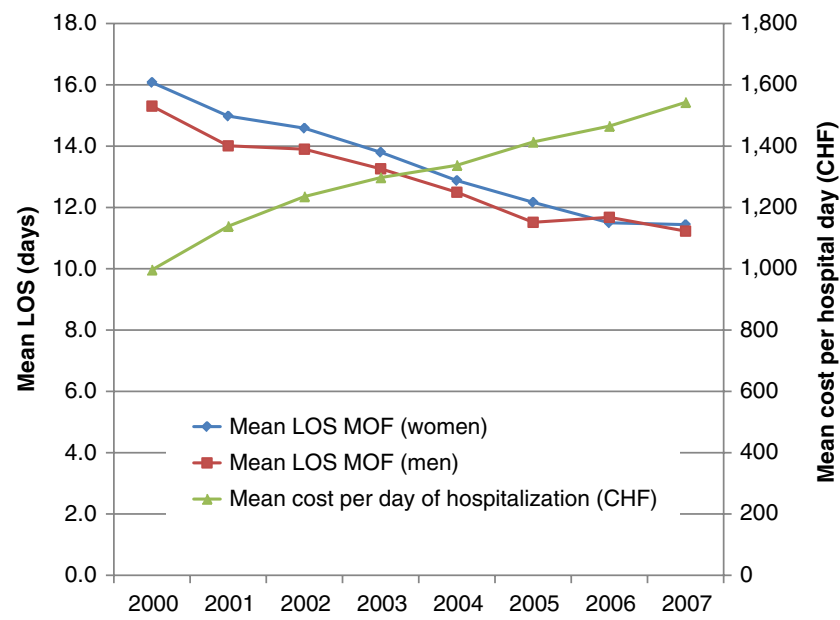

Fig. 3 Opposite trends in mean length of hospital stay (LOS) for all major osteoporotic fractures and in mean cost per day of hospitalization between years 2000 and 2007 old may have increased, especially in nursing homes, since vitamin D supplementation was first shown to reduce hip fractures in institutionalized elderly [37]. Similarly, one may speculate that the use of hip protectors [38-40] and the dissemination of information about fall prevention measures $[41,42]$ may have contributed to the decrease. However, the largest decrease in incidence was not seen in patients aged 85 years or older. Finally, the prevalence of osteoporosis itself may simply be declining, as suggested by the latest findings of the NHANES 2005-2006 survey which showed a decrease of the age-adjusted prevalence of osteoporosis measured by DXA at the femoral neck of 7\% in women and $3 \%$ in men compared to the NHANES III (1988-1994) survey [43]. No similar data are available for Switzerland.

The incidence of hospitalizations of major osteoporotic fractures other than of the hip increased during the same period in both sexes and in all age groups. This finding contrasts with earlier reports from Finland which indicated that low-trauma knee [44], ankle [45], and distal humeral 
[46] fractures may be stabilizing or even declining in this country. Importantly, the present analysis reports hospitalized fractures only. In an earlier work, we calculated that the hospitalization rates for all clinical spine fractures, fractures of the distal radius, and fractures of the proximal humerus were $22.3 \%, 34.1 \%$, and $52.6 \%$ in women aged 50 years or older [3]. The corresponding figures in men aged 50 years or older were $29.1 \%, 28.2 \%$, and $41.9 \%$, respectively [3]. Therefore, the probability of being hospitalized after a fracture may have increased at the expense of ambulatory treatment. This hypothesis may apply to clinical spine fractures, as vertebroplasties and kyphoplasties are increasingly performed in patients with acute painful fractures of one or more vertebral bodies [47]. However, we are not aware of revisions or extensions of the indications for surgical repair of fractures of the radius and the humerus during the period of observation. In addition, the ongoing health care reform has fostered a shift from traditional inpatient care towards preferred ambulatory outpatient care which would rather plead in favor of a decreasing number of hospitalizations including for fractures [48].

The cost of all hospitalizations for major osteoporotic fractures increased in women and men over the study period, driven mainly by large increases in the cost of nonhip fractures. On average, the direct medical cost of hospitalized major osteoporotic fractures was CHF 365 million per year between years 2004 and 2007, and the mean cost per patient was approximately CHF 17,000 for both sexes. The length of hospital stay has considerably decreased between 2000 and 2007 for all major osteoporotic fractures. While this trend may reflect efforts in optimizing inpatient acute medical care and cost, the present analysis shows that the cost impact of these efforts was totally offset by the parallel increase in the average cost per day of hospitalization. Furthermore, it is reasonable to assume that a minimal duration of hospitalization for surgical fracture repair exists and will be reached during the coming years. Once this floor duration of hospitalization is achieved, cost optimization will depend on whether the daily cost of per day of hospitalization alone can be reduced and possibly more realistically on the ability to avoid hospitalizations by preventing osteoporotic fractures through targeted interventions in populations at risk.

The present analysis showed that the total number of fractures leading to hospitalization increased from 2000 to 2007 in a population (45 years or older) that increased in number over the same period. This is also the first report of an increase in incidence of major osteoporotic fractures other than the hip, a finding that may be of considerable relevance. Typical sites of osteoporotic fractures may vary in their susceptibility to fracture and their response to intervention [49-52]. This would suggest that interventions aimed at reducing fracture risk should not only document their efficacy against vertebral and pooled non-vertebral fractures (including hip fractures), but also with regard to individual major osteoporotic fractures, namely fractures of the distal radius and the proximal humerus, and possibly other fracture types. As a consequence, certain patients may be shown to benefit more from certain interventions than from others. If so, these patients could be identified by means of a fracture site-specific risk assessment tool that offers improvements over FRAX [2, 3]. A nationwide fracture registry recording all hospitalized and nonhospitalized fragility fractures and the specific patient and fracture characteristics, including falls, would contribute to highlight the true changes in incidence of such fragility fractures, to study their correlation with underexplored risk factors such as falls, and to monitor the effects of interventions over time under "real-life" circumstances.

The present study has some limitations. The degree of completeness of patient records reporting increased from $81.2 \%$ in 2000 to $98.6 \%$ in 2007 , mainly due to new hospitals fulfilling their obligations. A selection bias cannot be excluded if hospitalizations for fractures were significantly different in these hospitals. However, reporting exceeded $95 \%$ as of 2002 , so that the magnitude of such a hypothetical bias is expectedly low. Only fracture patients hospitalized in acute settings were considered in the present analysis report, due to the lack of accessible fracture data in the outpatient sector in Switzerland. Therefore, the calculated incidences do not reflect the true incidence of osteoporotic fractures. Whether the proportions of hospitalized and non-hospitalized fractures reported in our earlier work [53] are still valid also remains unknown. Finally, our study was neither designed nor able to identify the exact causes of the reported findings.

In the rapidly aging Swiss population, hospitalizations for major osteoporotic fractures increased between years 2000 and 2007. The decreasing incidence of hip fractures was overcompensated by the increasing incidences of hospitalizations for clinical fractures of the spine, distal radius, and proximal humerus. The reduction in the mean length of stay observed for all fractures was offset by the accompanying increase in the daily cost of hospitalization. Further research is needed to confirm and better understand these trends.

Acknowledgments This work was supported by a research grant from Amgen Switzerland AG. We are grateful to Dr. Philippe Kress, Kressmed, Glattbrugg, Switzerland for his contribution to data analysis and his critical review of the manuscript. Amgen (Europe) $\mathrm{GmbH}$ and GlaxoSmithKline Ltd provided funds to Bioscript Stirling Ltd for editing and styling support.

Conflicts of interest $\mathrm{K}$. Lippuner has received research grants through the Osteoporosis Policlinic, University of Bern from Amgen, Novartis, Roche, Servier, and MSD. He has received speaker fees and/or was a member of a paid advisory board of Amgen, Daiichi Sankyo, Eli Lilly, MSD, Novartis, Nycomed Roche, and Servier. A. Popp has 
received consulting fees from Amgen, Eli Lilly, and MSD and also Speakers bureau from Daiichi-Sankyo, and Synthes. P. Schwab, C. Senn, and R. Perrelet have nothing to declare. M. Gitlin and T. Schaufler are employees of Amgen and may own stock and/or stock options.

\section{References}

1. (1993) Consensus development conference: diagnosis, prophylaxis, and treatment of osteoporosis. Am J Med 94:646-650

2. Lippuner K, Johansson H, Kanis JA et al (2010) FRAX assessment of osteoporotic fracture probability in Switzerland. Osteoporos Int 21:381-389

3. Lippuner K, Johansson H, Kanis JA et al (2009) Remaining lifetime and absolute 10-year probabilities of osteoporotic fracture in Swiss men and women. Osteoporos Int 20:1131-1140

4. Kanis JA, Burlet N, Cooper C et al (2008) European guidance for the diagnosis and management of osteoporosis in postmenopausal women. Osteoporos Int 19:399-428

5. Melton LJ 3rd, Kearns AE, Atkinson EJ et al (2009) Secular trends in hip fracture incidence and recurrence. Osteoporos Int 20:687-694

6. Gehlbach SH, Avrunin JS, Puleo E (2007) Trends in hospital care for hip fractures. Osteoporos Int 18:585-591

7. Brauer CA, Coca-Perraillon M, Cutler DM et al (2009) Incidence and mortality of hip fractures in the United States. JAMA 302:1573-1579

8. Leslie WD, O'Donnell S, Jean S et al (2009) Trends in hip fracture rates in Canada. JAMA 302:883-889

9. Jaglal S (2007) Falling hip fracture rates. J Bone Miner Res 22:1098, author reply 1099

10. Orimo H, Yaegashi Y, Onoda T et al (2009) Hip fracture incidence in Japan: estimates of new patients in 2007 and 20-year trends. Arch Osteoporos 4:71-77

11. Kannus P, Niemi S, Parkkari J et al (2006) Nationwide decline in incidence of hip fracture. J Bone Miner Res 21:1836-1838

12. Abrahamsen B, Vestergaard P (2010) Declining incidence of hip fractures and the extent of use of anti-osteoporotic therapy in Denmark 1997-2006. Osteoporos Int 21:373-380

13. Maravic M, Taupin P, Landais $P$ et al (2010) Change in hip fracture incidence over the last 6 years in France. Osteoporos Int. doi:10.1007/s00198-010-1255-9

14. Chevalley T, Guilley E, Herrmann FR et al (2007) Incidence of hip fracture over a 10-year period (1991-2000): reversal of a secular trend. Bone 40:1284-1289

15. Guilley E, Chevalley T, Herrmann F et al (2008) Reversal of the hip fracture secular trend is related to a decrease in the incidence in institution-dwelling elderly women. Osteoporos Int 19:1741-1747

16. Mann E, Icks A, Haastert B et al (2008) Hip fracture incidence in the elderly in Austria: an epidemiological study covering the years 1994-2006. BMC Geriatr 8:35

17. Hernandez JL, Olmos JM, Alonso MA et al (2006) Trend in hip fracture epidemiology over a 14-year period in a Spanish population. Osteoporos Int 17:464-470

18. Wildner M, Clark DE (2001) Hip fracture incidence in East and West Germany: reassessement ten years after unification. Osteoporos Int 12:136-139

19. Icks A, Haastert B, Wildner M et al (2008) Trend of hip fracture incidence in Germany 1995-2004: a population-based study. Osteoporos Int 19:1139-1145

20. Lippuner K, Golder M, Greiner R (2005) Epidemiology and direct medical costs of osteoporotic fractures in men and women in Switzerland. Osteoporos Int 16(Suppl 2):S8-S17
21. Lippuner K, von Overbeck J, Perrelet R et al (1997) Incidence and direct medical costs of hospitalizations due to osteoporotic fractures in Switzerland. Osteoporos Int 7:414-425

22. (2009) Swiss Federal Statistical Office. Plausibility of medical statistics: the MedPlaus 5.0 concept. Available online under $\leq \mathrm{http} / /$ www.freudiger.com/download/mp5_konzept_D_20091029.pdf $\geq$. Accessed Oct 2010

23. (2004) Swiss Federal Statistical Office. Data quality evaluation of medical statistics in 1998-2001. Available online under $\leq \mathrm{http}: / /$ www.bfs.admin.ch/bfs/portal/de/index/themen/14/22/publ.html? publicationID $=1306 \geq$. Accessed Oct 2010

24. Lewinnek GE, Kelsey J, White AA 3rd et al (1980) The significance and a comparative analysis of the epidemiology of hip fractures. Clin Orthop Relat Res 152:35-43

25. (2009) Swiss Federal Statistical Office. Hospital statistics between year 2000 and year 2007. Available online under http://www.bfs. admin.ch/bfs/portal/de/index/themen/14/03/01/data/01.html and http://www.bfs.admin.ch/bfs/portal/de/index/themen/14/03/01/key/ 01.html. Accessed 15 Feb 2010

26. Robine JM, Paccaud F (2005) Nonagenarians and centenarians in Switzerland, 1860-2001: a demographic analysis. J Epidemiol Community Health 59:31-37

27. Mathers CD, Murray CJL, Lopez AD et al (2001) World Health Organization global programme on evidence for health policy. Discussion Paper No. 38 http://www.who.int/healthinfo/paper38. pdf. Accessed 13 May 2006

28. Bundesamt für Statistik: Mortality and life expectancy tables. http://www.bfs.admin.ch/bfs/portal/de/index/themen/01/06/blank/ key/04.html. Accessed 20 Feb 2010

29. Bundesamt für Statistik. Szenarien zur Bevölkerungsentwicklung der Schweiz 2005-2050. http://www.bfs.admin.ch/bfs/portal/de/ index/news/publikationen.Document.83713.pdf. Accessed 14 May 2008

30. Bergstrom U, Jonsson H, Gustafson Y et al (2009) The hip fracture incidence curve is shifting to the right. Acta Orthop 80:520-524

31. Rossouw JE, Anderson GL, Prentice RL et al (2002) Risks and benefits of estrogen plus progestin in healthy postmenopausal women: principal results from the Women's Health Initiative randomized controlled trial. JAMA 288:321-333

32. Beral V, Banks E, Reeves G (2002) Evidence from randomised trials on the long-term effects of hormone replacement therapy. Lancet 360:942-944

33. Meyer HE, Lofthus CM, Sogaard AJ et al (2009) Change in the use of hormone replacement therapy and the incidence of fracture in Oslo. Osteoporos Int 20:827-830

34. Black DM, Cummings SR, Karpf DB et al (1996) Randomised trial of effect of alendronate on risk of fracture in women with existing vertebral fractures. Fracture Intervention Trial Research Group. Lancet 348:1535-1541

35. Black DM, Delmas PD, Eastell R et al (2007) Once-yearly zoledronic acid for treatment of postmenopausal osteoporosis. N Engl J Med 356:1809-1822

36. Melton LJ 3rd, Kanis JA, Johnell O (2005) Potential impact of osteoporosis treatment on hip fracture trends. J Bone Miner Res 20:895-897

37. Chapuy MC, Arlot ME, Duboeuf F et al (1992) Vitamin D3 and calcium to prevent hip fractures in the elderly women. N Engl J Med 327:1637-1642

38. Birks YF, Porthouse J, Addie C et al (2004) Randomized controlled trial of hip protectors among women living in the community. Osteoporos Int 15:701-706

39. Harada A, Mizuno M, Takemura M et al (2001) Hip fracture prevention trial using hip protectors in Japanese nursing homes. Osteoporos Int 12:215-221 
40. Kiel DP, Magaziner J, Zimmerman S et al (2007) Efficacy of a hip protector to prevent hip fracture in nursing home residents: the HIP PRO randomized controlled trial. JAMA 298:413-422

41. Tinetti ME, Baker DI, King M et al (2008) Effect of dissemination of evidence in reducing injuries from falls. N Engl J Med 359:252-261

42. Dargent-Molina P, Favier F, Grandjean H et al (1996) Fall-related factors and risk of hip fracture: the EPIDOS prospective study. Lancet 348:145-149

43. Looker AC, Melton LJ 3rd, Harris TB et al (2010) Prevalence and trends in low femur bone density among older US adults: NHANES 2005-2006 compared with NHANES III. J Bone Miner Res 25:64-71

44. Kannus P, Niemi S, Parkkari J et al (2009) Declining incidence of low-trauma knee fractures in elderly women: nationwide statistics in Finland between 1970 and 2006. Osteoporos Int 20:43-46

45. Kannus P, Palvanen M, Niemi S et al (2008) Stabilizing incidence of low-trauma ankle fractures in elderly people Finnish statistics in 1970-2006 and prediction for the future. Bone 43:340-342

46. Palvanen M, Kannus P, Niemi S et al (2009) Secular trends in distal humeral fractures of elderly women: nationwide statistics in Finland between 1970 and 2007. Bone 46:1355-1358

47. Hulme PA, Krebs J, Ferguson SJ et al (2006) Vertebroplasty and kyphoplasty: a systematic review of 69 clinical studies. Spine (Phila Pa 1976) 31:1983-2001
48. (2004) 5-year comparison of the inpatient and outpatient costs between 1999 and 2003. Swiss Health Observatory OBSAN. http:// www.obsan.admin.ch/bfs/obsan/de/index/05/01.Document. 105404. pdf. Accessed 16 Jun 2010

49. Cranney A, Tugwell P, Zytaruk N et al (2002) Meta-analyses of therapies for postmenopausal osteoporosis. IV. Meta-analysis of raloxifene for the prevention and treatment of postmenopausal osteoporosis. Endocr Rev 23:524-528

50. Ettinger B, Black DM, Mitlak BH et al (1999) Reduction of vertebral fracture risk in postmenopausal women with osteoporosis treated with raloxifene: results from a 3-year randomized clinical trial. Multiple Outcomes of Raloxifene Evaluation (MORE) Investigators. JAMA 282:637-645

51. Siris ES, Harris ST, Eastell R et al (2005) Skeletal effects of raloxifene after 8 years: results from the continuing outcomes relevant to Evista (CORE) study. J Bone Miner Res 20:1514 1524

52. Tang BM, Eslick GD, Nowson C et al (2007) Use of calcium or calcium in combination with vitamin D supplementation to prevent fractures and bone loss in people aged 50 years and older: a meta-analysis. Lancet 370:657-666

53. Suhm N, Lamy O, Lippuner K (2008) Management of fragility fractures in Switzerland: results of a nationwide survey. Swiss Med Wkly 138:674-683 